\title{
ORGANON: ENTRE A HISTÓRIA E A MEMÓRIA NO INSTITUCIONAL ACADÊMICO-CIENTÍFICO DO SUL DO BRASIL
}

\author{
ORGANON: BETWEEN HISTORY AND MEMORY IN THE \\ INSTITUTIONAL ACADEMIC-SCIENTIFIC ENVIRONMENT IN \\ SOUTHERN BRAZIL
}

\author{
Amanda Eloína Scherer ${ }^{1}$ \\ Verli Petri da Silveira ${ }^{2}$
}

\begin{abstract}
Resumo: Nosso objetivo neste artigo é refletir sobre como uma revista acadêmico-científica, neste caso, a Organon, pode nos ajudar a compreender o processo de divulgação e circulação do conhecimento sobre a língua e a linguagem em uma época ainda sem a divisão disciplinar que conhecemos hoje, construindo, por meio de suas publicações, 60 anos de história. Por um lado, ela é um espaço propício para entendermos a fundação e a constituição dos estudos disciplinares sobre a linguagem e, ao mesmo tempo, a sua institucionalização. Por outro lado, através dela, podemos entender também não só a história, mas também a importância de uma política científica editorial para o fazer acadêmico de uma determinada época. Nosso estudo está amparado, teórica e analiticamente, pela relação entre a História das Ideias Linguísticas e a Análise de Discurso tal como vem sendo construída no horizonte brasileiro.
\end{abstract}

Palavras-chave: história, memória, constituição disciplinar, política científica, institucionalização do saber, Revista Organon.

Abstract: Our goal in this article is to reflect on how an academic and scientific journal, in this case, Organon, can help us understand the process of dissemination and circulation of knowledge on language at a time without the disciplinary division we know today, building 60-year history. On the one hand, it is a space to understand the foundation and the constitution of the disciplinary studies on language at the same time as its institutionalization. On the other hand, through it, we can also understand the story of a scientific

1 Doutora em Linguística, Semiótica e Comunicação pela Université de Franche-Comté, Besançon, França. Professora Titular de Linguística da UFSM.

2 Doutora em Letras pela UFRGS e pós-doutora na Universidade Estadual de Campinas. Atualmente é professora associada da UFSM. 
editorial policy and its importance for academic work of a certain time. Our study is theoretically and analytically supported by the relationship between the History of Linguistic Ideas and Discourse Analysis as being built in the Brazilian context.

Keywords: history, memory, disciplinary constitution, scientific policy, institutionalization of knowledge, Journal Organon.

\section{Situando nossa problemática}

"la connaissance est um mode d'existance qu'il ne faut confondre avec aucun autre parce qu'elle mêle de mille façon originales aussi bien la distinction entre fabriquer et représenter que celle entre l'objet et le sujet." (Bruno Latour, 2012, p. 14)

As revistas acadêmico-científicas constituem-se, para nós, como publicações periódicas produzidas em instituições, através de seus centros de pesquisa, universidades e órgãos de apoio, as quais, por sua vez, divulgam artigos resultantes de pesquisas levadas a cabo por uma dada comunidade. São publicadas a intervalos regulares, sob a responsabilidade de uma equipe editorial. Consideramos que, por meio das revistas acadêmicas,

pesquisadores, grupos de pesquisa, estudantes em pós-graduação e professores universitários mantém uma ligação entre o que/como se faz em pesquisa e entre teoria e prática. Toda a revista é coletiva por natureza mesmo que pertença a uma só instituição universitária. É o caso da maioria das revistas acadêmicas no Brasil. Estas, quase sempre, são organizadas por intelectuais conhecidos em suas áreas e estes procuram desenvolver seus produtos para uma massa de leitores-consumidores, sempre visando firmar as necessidades do campo simbólico de seus instrumentos culturais e acadêmicos (SCHERER, 2003, p. 73).

O público alvo desse tipo de revista é a própria comunidade de pesquisadores e de estudantes em formação para a pesquisa, onde a revista

3 Tradução nossa: "o conhecimento é um modo de existência que não podemos confundir com nenhum outro, porque ele mistura de mil maneiras, todas originais, tão bem a distinção entre fabricar e representar como aquela entre o objeto e o sujeito."

Organon, Porto Alegre, v. 30, n. 59, p. 15-39, jul/dez. 2015. 
se insere, e no conjunto de universidades do país e do exterior. As revistas científico-acadêmicas são um importante meio de divulgação e circulação do que se produz como ciência e no como esse científico é posto em funcionamento. Por meio dessas publicações, podemos entender todo um percurso histórico de produção do conhecimento e podemos, igualmente, identificar e descrever a tradição de pesquisa à qual o pesquisador e ou a instituição em que ele está filiado põe em prática o seu fazer.

Se, por um lado, consideramos que a divulgação e a circulação do conhecimento dizem respeito a trajetos de dizeres que se dão em certas conjunturas (GUIMARÃES, 2013), que a divulgação e a circulação acontecem por meios que nunca são neutros (ORLANDI, 2001) e que, na instância da divulgação e da circulação, vários são os modos de sua visibilidade; por outro, precisamos igualmente considerar que os modos de divulgação e circulação do conhecimento estão relacionados às condições de produção "do que" e "do como se faz um saber", um saber científico, do "como se produz" e do "que se faz como ciência" em cada comunidade envolvida em cada uma das áreas assim caracterizadas nacionalmente a partir de políticas públicas de financiamento.

Partindo da premissa de que "não há ciência que não se assente em pressupostos (teorias) políticos e cujos resultados, em sua prática, não tenham consequências sobre os sujeitos, a sociedade e a história" (cf. OR$\mathrm{LANDI}^{4}$ ), podemos desde já afirmar que divulgar e fazer circular o conhecimento produzido também é um ato político por sua própria natureza. Inclusive, Orlandi e Guimarães (2006, p. 07), ao abordarem a questão da divulgação e da circulação das Ciências Humanas, entre elas, as Ciências da Linguagem, destacam a importância de se ter um entendimento tanto do processo histórico da divulgação e da circulação, ou seja, de como elas podem nos ajudar a compreender as práticas científicas, os conceitos e noções postos à prova, quanto do/de como esses são praticados em determinado momento, instaurando um movimento de sentidos interessante do ponto de vista da História da Ideias Linguísticas que praticamos. De acordo com os autores:

não se pode prescindir de pensar as práticas científicas das ciências da linguagem hoje sem considerá-las no processo da história das ideias linguísticas e das teorias sobre a linguagem. E ao mesmo tempo saber entender as especificidades destas práticas no momento atual (GUIMARÃES; ORLANDI, 2006, p. 07).

4 HIL: Conhecimento e Política de Línguas. Disponível em: <http://www.unicamp.br/iel/hil/ projeto_conhecimento.html>. Acesso em 22 de maio de 2015. 
Tais considerações reforçam a ideia de que é preciso conhecer a história e igualmente compreender a constituição de uma memória coletiva para, de fato, entender como se dá a produção científica em uma dada área do conhecimento, naquilo que Chevalier (2006) denomina como a história social da linguística.

Para nós, a divulgação e a circulação estão, por sua vez, atreladas a um rigor institucional ${ }^{5}$. Pfeiffer (2007) considera que esse processo toca o espaço político-social e, ao pensarmos, portanto, no processo de institucionalização dos estudos sobre a linguagem no sul, a partir de revistas acadêmico-científicas, vamos, obrigatoriamente, refletir sobre o político que as sustenta. De acordo com Pfeiffer (2007, p. 21), colocar o político como estruturante do conhecimento científico é uma contribuição indiscutível e, acrescentamos, ele é constitutivo de uma história em uma certa memória. Para Orlandi (2008, p. 40), inclusive,

Se por um lado, tudo é político, e de outro tem-se procurado minimizar ou desprezar a importância do político, não é menos verdade que hoje é mais ou menos claro para todo intelectual que o que ele produz como conhecimento é submetido já de saída a tensões que nascem de embates que nada tem a ver com a pretensa neutralidade da Ciência, mas com as relações de força que presidem um imaginário social como o nosso (Orlandi, 2008, p. 40).

É preciso refletir sobre tais questões quando estamos construindo a história de uma tradição na produção do conhecimento, pois ela está igualmente calcada em instrumentos linguísticos e culturais. $\mathrm{Na}$ contemporaneidade, é possível afirmar que "produzir conhecimento é um trabalho permanente de demarcação, de lugares, trabalho que exige um policiamento incessante de fronteiras e uma vigilância epistemológica ímpar de domínios"; isto para que possamos "manter as rédeas da nossa sujeição nos possíveis deslizamentos de sentido na constituição do campo do saber em que estamos postos" (SCHERER, 2008, p. 133). De fato, é necessário observar que:

Produzir ciência é produzir conhecimento em uma certa ordem, em uma certa época, em certas condições de produção. A partir desse entendimento, recorro a Stengers (1987), quando

5 Cf. LAZZERI, 2002, p.7. 
a mesma afirma que os conceitos são nômades pela natureza da história da ciência com espaço-tempo-lugar bem marcados (SCHERER, 2008, p. 133).

Diante disso, avaliamos que as revistas científico-acadêmicas têm o papel relevante de institucionalizar uma ideia, uma teoria, até mesmo fazer nascer um novo campo, na medida em que se constituem como um espaço capaz de produzir unidade e dar legitimidade ao que se faz e ao que se produz enquanto conhecimento. Entendemos que, colada à questão da institucionalização do saber, se dá, muitas vezes, o processo de disciplinarização de uma área ou subárea da produção do conhecimento, o que merece especial atenção quando estamos estudando a história e a memória que fazem de uma revista científico-acadêmica o que ela é.

Vamos apresentar aqui, muito resumidamente, o contexto histórico de como se efetiva a criação de uma política de revistas em geral no espaço brasileiro para podermos entender melhor as suas condições de produção. Se as tomarmos, historicamente, podemos afirmar que, no início do século 19, começaram a ganhar espaço e corpo revistas cujos títulos tratavam de interesses gerais, desde entretenimento até questões da vida familiar. É nesse período também que surge a primeira revista feita no Brasil: As Variedades ou Ensaios de Literatura, criada em 1812, em Salvador, e que, na verdade, tinha muito mais um aspecto de livro do que propriamente de uma revista. Ela abordava temas considerados à época como eruditos: costumes e virtudes sociais, fragmentos de história antiga e moderna, bem como fragmentos de textos de autores clássicos portugueses, entre outros. Pouco tempo depois, em 1839, nascia a Revista do Instituto Histórico e Geográfico Brasileiro, que abordava, por sua vez, temas culturais e científicos. Depois começam a ser editadas, cada vez mais, revistas de cunho acadêmico e artístico. Vamos citar aqui apenas duas que dispomos, em edições completas, em nosso centro de documentação ${ }^{6}$, e que são de interesse de nosso grupo de pesquisadores. São elas: a Revista Lanterna Verde, publicada entre 1934 e 1944 pela Sociedade Felipe d'Oliveira, no Rio de Janeiro; e a Revista Província de São Pedro, publicada de 1945 a 1957 pela Livraria do Globo, em Porto Alegre. As duas trazem muito da relação entre o artístico e o regional, o que, praticamente, não teremos quase mais (pelo menos da forma até então apresentada) nas décadas seguintes.

6 Cf. Acervo de obras raras do Laboratório Corpus, do Programa de Pós-Graduação em Letras da UFSM. 
A pesquisa realizada por Paim $\left(2013^{7}\right)$ revela que, no sul do Brasil, as décadas de 50 e 60 do século XX são marcadas pela fundação de revistas que divulgavam a produção do conhecimento na área de Letras e Ciências Humanas, dentre as quais destaca-se: Revista Letras, fundada em 1953, sendo ela uma publicação do Curso de Letras Clássicas, Neolatinas e Anglo-Germânicas da Faculdade de Filosofia Ciências e Letras da Universidade Federal do Paraná; e também a Revista Organon, fundada em 1956, publicação da Faculdade de Filosofia da Universidade Federal do Rio Grande do Sul. Depois, nos anos 1960, teremos a revista Alfa, em 1962, que surge como uma publicação da Faculdade de Filosofia Ciências e Letras de Marília (SP) e a revista Letras de Hoje, fundada em 1967 e publicada pelo Departamento de Letras da Faculdade de Filosofia da Pontifícia Universidade Católica do Rio Grande do Sul.

No que se refere à revista Organon, objeto de nosso estudo, ela completa 60 anos de fundação em 2016. Ela teve publicação regular de 1956 até 1969, quando foi, também, extinta a faculdade na qual foi fundada. Até então foram publicados 14 números. É em 1986 que o Instituto de Letras, criado a partir do antigo Departamento de Letras da Faculdade de Filosofia, retoma a publicação da Organon, dando a ela um novo estatuto. Desde então, foram publicados 57 números. Em nossa avaliação, ela será um marco fundador e um relevante espaço de circulação de saberes sobre a linguagem, a partir do qual é possível observar como se dá a produção, a divulgação e a circulação do conhecimento linguístico e literário em quase 60 anos de história das ideias acadêmicas e editoriais no sul do Brasil ${ }^{8}$. As revistas científico-acadêmicas, assim como outros instrumentos, possibilitam-nos compreender:

como as questões linguísticas aparecem em cada momento histórico, sem, no entanto, reduzirmos nossa reflexão a uma cronologia temporal. Cada momento histórico precisa ser tomado enquanto espaço de circunstancialização, a partir do qual é possível compreender as condições de produção de cada discurso para podermos historicizar suas evidências subjetivas. De fato, queremos mostrar que história e memória não estão desvencilhadas quando se trata da recuperação dos modos de institucionalização da Linguística no e do Brasil. (SCHERER; PETRI, 2012, p. 73-74)

7 PAIM, Z. M. V. "O caráter 'móvel': uma reflexão a cerca do processo de construção do arquivo de revistas acadêmicas". 61 Seminário do GEL. FFLCH/USP. São Paulo (SP, jul./2013) e no prelo (Pesquisa realizada em seu estágio pós-doutoral - PNPD CAPES).

8 Cf. Projeto de Pesquisa: "Linguística no sul: estudo das ideias e organização da memória" (desde 2012, na sua quarta etapa), sob a coordenação de Amanda Scherer e participação de Verli Petri, entre outros pesquisadores. 
De fato, vamos nos deter aqui, na Organon, olhando-a do ponto vista da ciência linguística, essa que estamos designando, de forma mais abrangente, como aquela da produção do conhecimento dos estudos sobre a linguagem. Justificamos nossa escolha pelo fato de que não teremos tempo nem espaço para estudar mais de perto, por exemplo, o funcionamento do próprio do disciplinar e, ainda, o modo de como vamos passar de reflexões do campo da Filologia e dos estudos históricos sobre a linguagem ao que somos hoje enquanto área de conhecimento.

\section{Organon: entre uma história institucional e uma memória acadêmica ...}

"On ne maîtrise pas les pratiques scientifiques sans se maîtriser soi-même, sans cultiver assidument un certain type de soi"9. (Daston; Galison, 2012, p. 52)

O ponto de partida de nossa reflexão é a fundação da $\operatorname{Organon}^{10}$, vinculada à Direção da Faculdade de Filosofia da Universidade do Rio Grande do Sul. Tal ponto conduz-nos a elencar alguns elementos constitutivos das condições de produção e, por esse viés, a primeira questão que se coloca é: como se dá a produção, a divulgação e a circulação do conhecimento no interior da instituição nos anos de 1950 e 60? Como sabemos, tal década é marcada por grande efervescência, sobretudo, no interior da Faculdade de Filosofia, a qual integrava diversos outros cursos, tais como Física, Química, Letras, etc., já com vistas a uma produção do conhecimento sistematizada na forma de artigos. É preciso ressaltar que, nessa época, havia uma ênfase muito grande na produção e no avanço de questões metodológicas de pesquisa, bem como no desenvolvimento de atividades que pudessem auxiliar no campo do ensino, em detrimento do que se conhece hoje como científico. Podemos, por exemplo, observar como se dá o processo de institucionalização, divulgação e circulação do saber produzido no interior da referida faculdade, posto que, naquele momento:

A atividade de pesquisa é definida e enquadrada nos objetivos de formação e nos quadros de trabalho docente da Universi-

9 Tradução nossa: "A gente não domina as práticas científicas sem dominar a si mesmo, sem cultivar de forma assídua um certo tipo de eu."

10 Trabalhamos, por uma tomada de posição analítica, com a edição completa de todos os números da Revista que estão disponíveis on line no site: http://seer.ufrgs.br/organon. Por isso, a listagem dos números citados neste artigo não aparecerá nas referências bibliográficas. 
dade: 'Os trabalhos de pesquisa devem ser conduzidos, sempre que possível, vinculadamente às cátedras', e que a atividade de investigação científica, no estágio em que se encontrava a Universidade, seria, essencialmente, uma atividade subsidiária ao ensino, tendo por objeto, antes de tudo, a formação de futuros pesquisadores e cientistas e o enriquecimento das atividades docentes $^{11}$ pela objetivação de técnicas e métodos de pesquisa ${ }^{12}$.

O editorial da primeira edição da Organon é assinado pelo Diretor da Faculdade $^{13}$, na época que a designa como "revista universitária" e "órgão universitário", que deve "ser a expressão de todos aqueles que se dedicam ao ensino e à investigação”. O prólogo traz também um esboço do que seria a cientificidade, a partir do pensador Karl Jaspers, revelando seu caráter opositivo: o que é em oposição ao que não é o fazer científico, marcando, sobretudo, a diferença entre dogma e ciência, quando a crença estaria para o dogmatismo assim como a verdade estaria para o científico. Finalizando a apresentação da revista, o Diretor almeja que ela seja "um instrumento de trabalho". Vejamos as palavras dele:

Não devemos nem podemos assinalar a rota que tomará a nossa Organon. Só queremos pedir-lhe o que em seu nome já transparece: ser um instrumento de trabalho, são e eficaz; que não abandone jamais a posição de um defensor inclemente do pensamento claro e livre; e que para existir autêntica e vitalmente - se incline para as nossas realidades, literárias, científicas e filosóficas, ainda tão virgens, e tão ávidas por receberem a atenção de nossos mestres e investigadores.

Cabe notar que não há, nessa apresentação da Organon, qualquer determinação disciplinar, ficando em aberto o espaço de contribuições para as diferentes áreas às quais abarcava a Faculdade de Filosofia, bem como cumpre observar que não há alusões sobre quem poderia ou não publicar na Revista, o que será demarcado em outro momento, como por exemplo, em 1989, pois, a partir dessa edição, a Organon está aberta a contribuições de pesquisadores de outras instituições, em qualquer dos campos disciplinares da área de Letras e Linguística.

11 Grifos nossos.

12 Cf. http://www.ufrgs.br/ufrgs/a-ufrgs/historico, acesso em 28.06.2015.

13 Professor Luiz Pilla. 
Há dois elementos que nos chamam especial atenção ainda na Organon, $\mathrm{n}^{\circ} 1$ :

a) uma seção de resenhas de obras que estavam sendo publicadas na época, seção essa que depois desaparece, voltando a fazer parte da revista somente em sua fase mais atual; b) a informação que está na última página da revista, a qual consiste na solicitação de permuta em cinco línguas, o que é surpreendente em uma época anterior à internet, na qual era difícil e demorado realizar os trâmites de importação e exportação de livros e revistas. Pelos estudos que temos feito, observamos que, apesar de sabermos que tais revistas circulavam em diversas bibliotecas e em países como a França, a Alemanha, a Espanha, entre outros, e que boa parte dos linguistas e filólogos eram conhecedores de várias línguas, é recente o considerar como critério de avaliação a permuta e o lugar da língua estrangeira nessas/para essas publicações. Pudemos vivenciar essa realidade em uma visita à Biblioteca da Universidade de Grenoble, na França, nos anos 80: a Organon estava lá, com os 12 números iniciais, em uma secção designada como de revistas internacionais. Com certeza, caracteriza uma outra cultura no fazer acadêmico. Trazemos aqui o recorte para ilustrar tal questão:

\section{Pede-se permuta}

* Rogamos enviarnos en canje sus publicaciones

* Please send us your publications in exchange

* Nous prions de nous envoyer en échange votre publications

* Wir danken für Austausch

Interessante destacar a correção manuscrita do plural do pronome possessivo em francês que aparece na cópia escaneada na versão on line da referida revista. Para nós, isso tem a ver com a cultura material dessa época, ou seja, uma outra cultura material na feitura de um impresso com outros instrumentos tecnológicos. Um último destaque na edição $\mathrm{n}^{\circ} 1$, que nos chama especial atenção é a publicação do artigo de Serafim da Silva Netto, bem como de um artigo sobre o reconhecido filólogo brasileiro, escrito pelo professor Albino de Bem Veiga. O texto de Serafim da Silva Neto, intitulado "A renovação da filologia românica no séc. XX", aparece publicado na revista em questão como uma das atividades por ele desenvolvida 
em sua estada como professor visitante, no Curso de Letras na instituição àquela época. Por esses feitos, podemos afirmar que a área de Letras e Linguística da UFRGS não se via apenas agraciada com tal personalidade publicando na revista, mas, também, já podia se ver como a um exemplo na implementação de uma política de intercâmbio acadêmico, nacional e internacional. Segundo salienta Veiga (em sua apresentação), o Prof. Serafim ministrou seminários e proferiu conferências para o Curso de Letras, atividades que estariam inseridas em um programa de intercâmbio, para o qual já teriam feito parte Harri Meier (lusófono e estudioso do português), Herbert Minnemann (professor de língua e literatura portuguesa e brasileira no Instituto Ibero-americano da Universidade de Hamburgo) e o nosso mais conhecido, Gladstone Chaves de Mello. Destaca-se, portanto, aqui, as relações internacionais que se estabeleciam à época e em decorrência delas a necessidade de permuta de revistas e mesmo da publicação em diferentes línguas estrangeiras, mas, e sobretudo, o caráter de vanguarda da área no sul do país.

A presença de texto de Serafim da Silva Neto e a apresentação de Albino de Bem Veiga no primeiro número da Organon representa, para nós estudiosos e pesquisadores da história da linguística no sul, que os Estudos da Linguagem, nesse espaço de fundação de uma revista acadêmica com abrangência de trabalhos em diferentes áreas do conhecimento, tem um ponto importante a ser considerado nessa história. Como veremos, também, a seguir, a Organon teve algumas reformulações formais e de conteúdo temático, mas sempre manteve o compromisso marcado inicialmente de ser "um instrumento de trabalho são e eficaz; que não abandone jamais a posição de um defensor inclemente do pensamento claro e livre".

A partir de nosso estudo, a história da revista Organon estaria constituída em dois movimentos bem marcados na institucionalização dos estudos sobre a linguagem. Estamos propondo, aqui, uma proposta analítica bem própria, que subdivide a produção de quase 60 anos em dois movimentos: o primeiro, que vai de sua criação - 1956 - até o ano de 1969; e, o segundo, de 1986 até nossos dias.

O primeiro movimento - Da institucionalização ao científico - dá-se com a sua fundação em 1956 e traz, em seu bojo, como já assinalamos, a responsabilidade com a produção e divulgação do conhecimento produzido na Faculdade de Filosofia da, então, Universidade do Rio Grande do Sul. O texto apresentado, intitulado no sumário como Editorial, aparece apenas no primeiro número. Suas primeiras 14 edições trazem esporadicamente textos dos estudos sobre a linguagem, o que pode ser observado em 
uma análise mais descritiva dos sumários, posto que eles revelam pistas da constituição desse espaço de circulação do saber tanto no tocante aos autores quanto às temáticas que serão recorrentes e nos remeteriam à produção de um saber mais regionalizado nos estudos sobre linguagem. Vejamos o que podemos indicar:

1959, no 2 - "O tipo social gaúcho", de Lothar F. Hessel, que discute, entre outros elementos, a linguagem do gaúcho, as diferenças entre o falar gaúcho brasileiro e platino, bem como as diferentes acepções para o próprio termo "gaúcho".

1960, n 4 - "Notas linguístico-etnográficas sobre a erva-mate no Rio Grande do Sul”, de Heinrich A. W. Bunse, que discute questões linguísticas e etnográficas que ligam a produção da erva-mate à cultura gaúcha e, ao final do artigo, apresenta um glossário específico das palavras e expressões utilizadas nos ervais das missões.

$1963^{14}, n^{\circ} 8$ e 9 - "Comparações do linguajar diário do gaúcho", de Walter Spalding, que discute as diferentes expressões regionais utilizadas inicialmente pelos tropeiros, as quais, às vezes, podem ser de difícil compreensão para os demais gaúchos. Importa destacar aqui que, ao final do artigo, se tem uma nota que informa ao leitor que tal publicação reúne outras publicações menores já divulgadas no "Jornal do dia”, de Porto Alegre.

$1967, n^{\circ} 12 ; 1968, n^{\circ} 13$ - "A polivalência do verbo dar no sul do Brasil", de Lothar Hessel, que discute as particularidades dos usos que se faz do verbo dar em locuções no sul do Brasil. Ao final do artigo há uma nota entre parênteses que informa que tal discussão continua no próximo número da Organon $^{15}$.

1969, n 14 - "Notas etnológico-linguísticas sobre a moenda da cana-de-açúcar nas colônias alemãs do Rio Grande do Sul”, de Walter Koch, que discute a terminologia utilizada nesse espaço de trabalho específico, apresentando, ao final, um glossário.

São interesses e estudos que determinam uma época e que vão também nos ajudar a entendê-la na sua relação com a história do pensamento sobre a linguagem. Os estudos linguísticos no sul, segundo nossas pesquisas (DIAS; PETRI; SCHERER, 2015 ${ }^{16}$ ) têm uma relação muito forte com as políticas linguísticas vigentes naquela época e mostram-nos a sua relação

14 A partir de 1962, a até então Universidade do Rio Grande do Sul passa para Universidade Federal do Rio Grande do Sul, o que pode ser observado nas capas da Organon.

$15 \mathrm{O}$ que de fato acontece.

16 "Dialectiques: uma contribuição para a história da produção do conhecimento sobre a linguagem nos anos 60 e 70". In: BALDINI, L.; SOUSA, L. Análise de Discurso e materialismo histórico: língua, sujeito e ideologia, Editora da UNICAMP, 2015. (no prelo) 
com os estudos dos países vizinhos, chamados então de países do Prata. No que nos aproximamos e no que nos afastamos, eram questões propostas e determinantes para a constituição de um grupo social e o político no científico de então.

Já o segundo movimento - Do científico ao disciplinar - tem início em 1986, quando a revista ressurge com uma nova configuração, ISSN já na capa, com um texto de apresentação que explicita que ela teve edições regulares até 1969, quando foi extinta a Faculdade de Filosofia. A retomada da Revista e a publicação do ${ }^{\circ} 15$ se dá pelo esforço da congregação do Curso de Letras:

Com o objetivo de tornar conhecida a produção intelectual do Instituto de Letras, ORGANON será publicada semestralmente, destinando-se ainda a promover $o$ intercâmbio com public açōes congêneres brasileiras e internacionais.

Promovendo uma retomada no princípio estabelecido no número 1 (1956) que é a promoção do intercâmbio entre publicações da mesma natureza, ao final do texto, reafirma-se o compromisso firmado no Editorial da Organon número 1, voltando à baila a importância de se ser "instrumento de trabalho". Tal apresentação é assinada pela Direção do Instituto de Letras à época, Professora Vânia Lúcia de Barros Falcão. A temática da Organon, a partir desse momento, abrange tudo o que seja de interesse da área de Letras e Linguística, embora isso não esteja explicitado senão nos títulos do sumário. Os títulos alternam temáticas de língua, literatura e linguística, seguindo a ordem alfabética do primeiro nome de cada autor, sem o agrupamento por temática.

Na Organon, no 16, publicada em 1989, apresenta-se na capa a sua temática: "A mulher e a literatura" e traz uma seção intitulada Editorial, escrita pela Direção do Instituto de Letras, além de uma seção de Apresentação do número, escrito pela organizadora. Identifica-se aqui um marco diferencial na política editorial para além da continuidade da Organon, pois, nesse momento, ela adquire um caráter potencialmente científico-acadêmico, capaz de dar conta das demandas da época. Talvez pudéssemos dizer que o momento remonta a uma refundação da revista, ou, melhor dizendo, uma nova institucionalização, a partir de uma cientificidade latente em relação a uma representação da disciplinarização da produção do saber tal como a concebemos atualmente. É preciso dar especial atenção a este Editorial, pois nele talvez se evidencie melhor uma das causas da interrupção da publicação por quase 20 anos, conforme segue: 
Este nowo número da revista Organon assinala um momento, marca uma posiçăo e restaura um projeto. $\hat{\mathrm{E}}$ o primeiro da atual direção do Instituto de Letras da Universidade Federal do Rio Grande do Sul e retoma uma iniciativa de longa tradiçăo na vida desta casa, que os anos de arbítrio e acomodação se encarregaram de apagar: a de veicular idéias por escrito, para além das paredes das salas de aula e gabinetes, de modo a submetê-las à crítica e a integrá-las no esforço comum de alunos e professores para o crescimento qualitativo da educaçฐ̃o superior.

A referência aos "anos de arbítrio" remete-nos à ditadura militar e às diversas situações de censura que a universidade brasileira viveu nos anos finais da década de 1960 e das décadas de 1970-80. Não é uma simples coincidência ter o ano de 1989 como aquele no qual se dá a reabertura democrática no cenário político brasileiro e que se torna possível dizer isso abertamente no editorial de uma revista universitária, como é o caso da Organon.

É nesse momento que a Revista abre-se para a produção do Instituto de Letras da UFRGS e também para outras produções externas, delineando um espaço de circulação diferenciado do que se tinha até então. Há também uma preocupação com a popularização da ciência que não havia sido explicitada antes, já que uma revista universitária, segundo Guimarães nos diz no Editorial, é "financiada pelo contribuinte brasileiro, não pode encerrar-se dentro da academia", bem como deve "por em circulação o que se sabe sobre a linguagem e a arte verbal, uma vez que estas pertencem a todos os cidadãos" (GUIMARÃES, 1989, p. 9).

É em 1993 que a Organon ganha a organização mais próxima do que conhecemos hoje, conforme explicitado no Editorial da número 20:

primeira, já presente nos números anteriormente mencionados, organiza-se em torno de um núclco temático. A scgunda caracteriza-se por scr uma seçåo aberta a trabalhos que não se enquadrem na temática anterior $\mathrm{c}$ a última publica resenhas.

Scus números semestrais, dedicados alternadamente a questões de lingua/lingüistica, literatura/teoria literária serão publicados sob a responsabilida-

Interessante também é demarcação "língua-linguística" e literatura- teoria literária que novamente não teremos tempo e espaço para nos determos nela para refletirmos sobre os campos disciplinares que ela engendra. E, destacamos igualmente a nova forma, ganhando uma outra estrutura institucional: 
A Organon constituiu um Consclho Editorial amplo e multidisciplinar, integrado por doutores $\mathrm{em}$ diferentes áreas do conhecimento lingüistico e literário. de âmbito local, nacional e internacional, com a função especifica de emitir parecer sobre os trabalhos encaminhados a publicação. Tal consclho dará um perfil nacional e internacional à Organon, bem como lhe atribuirá uma feıção de periódico cientifico.

O presente número divulga igualmente as normas para encaminhamento de trabalhos. Desse modo, obedecidos tais critérios, a Organon está aberta a contribuiçócs representativas do amplo leque que compōe o conhecimento de Letras.

É no ano de 1996 que entra em circulação a Organon número 23 (concebida em 1995, em contraponto à massiva publicação temática da área de estudos literários apresentada até então), com a temática "O texto em perspectiva" e que se consolida efetivamente o periódico científico como representativo dos estudos sobre a linguagem, destacando a importância de um objeto e de diferentes teorias em pleno desenvolvimento e funcionamento na época. De fato, tal número esgotou-se em pouco tempo e teve sua reimpressão em 2001.

Será com a Organon número 24, que sinaliza a comemoração dos 40 anos de sua fundação, que há um reconhecimento institucional explicitado no Editorial, pois a partir de então, além do apoio da Direção do Instituto de Letras, a Pró-Reitoria de Pesquisa - PROPESQ, via Programa de Apoio à Editoração de Periódicos, passa a ser uma fonte de recursos para que a publicação aconteça com a qualidade desejada.

O Editorial da Organon até 1989 é assinado pela Direção do Instituto de Letras, movimentando-se depois para uma fase de maior autonomia, passando a existir uma direção da Revista; mesmo vinculada, institucionalmente, à Direção do Instituto de Letras, ela começa a ter uma vida própria enquanto editoria, diríamos nós, mais independente, mas já tomada pelas políticas de avaliação e implementação de criação de novas revistas acadêmico-científicas pela CAPES. É na edição de número 32/33, de 2002, sob a temática "Estudos enunciativos: a diversidade de um campo", que o Editorial explicita o lugar conquistado por tal periódico no campo da produção e divulgação do conhecimento dos estudos sobre a linguagem: "por tudo quanto precede, espero que este número de Organon cumpra sua função de instrumento de divulgação da pesquisa que se faz hoje em um dos campos dos estudos da linguagem, tanto em nossa universidade quanto em outras universidades do país" (INDURSKY, 2002).

Foram inúmeros os desafios que a Organon vai precisar superar para 
tornar-se o periódico científico reconhecido que é hoje. Um deles, conforme está pontuado no Editorial da número 35, de 2003, sob a temática "Língua, discurso, memória", é que a regularidade de publicação semestral tem o seu ápice maior: o "número 35 finalmente coloca a Organon em uma situação de regularidade, há já algum tempo desejada e anunciada, mas nunca antes alcançada. (...) o segundo número do volume 17 , que corresponde ao segundo semestre de 2003, sai do prelo no segundo semestre de 2003" (INDURSKY $\left.{ }^{17}, 2003\right)$. Neste momento a Organon se afirma "sem nenhum favor, entre os bons periódicos acadêmicos do país” (Idem).

$\mathrm{Na}$ edição de número 25, sob a temática "A língua materna: o ensino em processo", há dois elementos que nos chamam especial atenção no Editorial: primeiro, a explicitação de uma relação de intercâmbio interinstitucional, pois "colaboram vários pesquisadores da UFRGS e da UNICAMP, apresentando uma série de trabalhos em torno dessa problemática" (INDURSKY, 1997); e, segundo, a publicação do artigo de Sylvain Auroux intitulado "Les limites de la grammaire", na seção livre ${ }^{18}$. Tal publicação explicita a presença de um importante teórico para a História das Ciências -sempre referenciado no campo disciplinar da História das Ideias Linguísticas no espaço universitário internacional. A questão que nos intriga é: seria o fundacional de um outro campo disciplinar que começa a ter visibilidade no interior da Organon?

A Organon número 26, também dedicada aos Estudos da Linguagem, apresenta como temática “Terminologia e Integração", explicita as relações acadêmicas interinstitucionais e internacionais, dando especial ênfase ao Mercosul, criado em meados dos anos 90 do século XX, em pleno processo de institucionalização e consolidação na época da publicação deste número da Revista. Para além do que é explicitado no Editorial, trazemos parte da Apresentação do referido número que detalha a ação conjunta, cujos resultados constituem os textos apresentados:

O estudo da terminologia, que motiva este número da revista Organon, também constitui o núcleo do projeto Bases teórico-metodológicas para o desenvolvimento da terminologia no Mercosul $^{19}$, do qual participam docentes do Instituto de Letras da UFRGS, do Projeto TERMISUL, e docentes da Faculdade de

17 Este Editorial merece especial destaque, posto que recupera boa parte da história da Organon, tecendo comentários bastante pertinentes.

18 Itálico da autora do editorial.

19 Grifo da autora da Apresentação.

Organon, Porto Alegre, v. 30, n. 59, p. 15-39, jul/dez. 2015. 
Filosofia e Letras da Universidade de Buenos Aires e do Instituto de Desenvolvimento Humano da Universidade Nacional de General Sarmiento, membros do TERMTEX. (KRIEGER, 1998, s/p)

Além disso, na Apresentação, consta uma nota de rodapé que traz informações adicionais importantes para nossa compreensão da fase do processo de inter-relações entre diferentes grupos de pesquisadores que fazem da Organon o que ela é hoje, bem como aparecem representados os órgãos de fomento que apoiavam o projeto conjunto.

A primeira Organon do século XXI, número 28/29, sob a temática "Estudos da língua falada”, mantém o fio condutor observado nos últimos números dedicados aos Estudos da Linguagem, posto que em seu Editorial é possível identificar o destaque dado às relações entre pesquisadores de diferentes instituições, nacionais e internacionais, que se interessam pela temática, conforme segue:

Este número duplo da Revista Organon (...) traz estudos sobre o Português falado no Sul do Brasil, mais especificamente, no Rio Grande do Sul, Santa Catarina e Paraná. Tais estudos foram feitos tomando como enfoque teórico a sociolingüística quantitativa, envolvendo pesquisadores do Instituto de Letras desta Universidade, estudantes de Iniciação Científica vinculados ao VARSUL, mestrandos e doutorandos da PUC/RS e da UFSC, bem como pesquisadores de outras Instituições Universitárias do Sul do Brasil (UFPR, UFSC, UNESC). Este número abre com o artigo de Gregory Guy, professor da York University, Toronto e da New York University, USA, que atuou como professor visitante no Instituto de Letras desta Universidade e é pesquisador associado ao VARSUL. (INDURSKY, 2000).

Já a Organon 32/33, dedicada à temática "Estudos enunciativos: a diversidade de um campo", além de dar continuidade à política editorial que dá ênfase às relações entre pesquisadores de diferentes instituições, revela a preocupação com a "sua função de instrumento de divulgação da pesquisa que se faz hoje em um dos campos dos estudos da linguagem, tanto em nossa universidade quanto em outras universidades do país" (INDURSKY, 2002). Chama-nos especial atenção a palavra "divulgação", pois os periódicos vão cada vez mais aprimorando seu papel no interior da comunidade científico-acadêmica, e isso também ocorre na história da Linguística no 
sul do Brasil. Inclusive, a ênfase no espaço de divulgação acentua-se na Organon número 35, sob a temática "Língua, discurso, memória", pois ela é descrita como "uma vitrina do que está sendo produzido em Análise do Discurso no Brasil” (INDURSKY, 2003).

A Organon 36 inaugura uma nova fase para a revista, no tocante aos Estudos da Linguagem, dedicada aos "Estudos de fonologia e morfologia", conforme ilustra o primeiro parágrafo do Editorial:

Esta edição da Revista ORGANON do Instituto de Letras corresponde ao segundo número dentro de uma nova proposta editorial, em que se privilegiou a modernidade e a plasticidade, com a logomarca com as letras do nome da revista, representada pela esfera azul, e com a estrutura textual do miolo da Revista disposta em colunas para um ritmo fácil de leitura. Na capa, a letra $\mathrm{B}$ sugere a ordem lógica editorial do segundo número (MONARETO, 2004).

Tal formato terá apenas 3 edições, A B e C, voltando depois ao seu formato anterior, conforme é explicitado no Editorial da Organon 38/39, dedicada aos Estudos Literários, "Essa edição da Revista Organon corresponde ao primeiro número de retorno ao formato anterior" (FLORES; MELLO, 2005, p. 8).

A Organon número 40/41, sob a temática "Linguagem e sintoma", tem seu editorial assinado por uma dupla de Editores, um representante da área de Estudos da Linguagem e outro de Estudos Literários, como já vinha acontecendo desde o número 38. Tal Editorial destaca a importância da Revista no cenário nacional e o esforço para manter a periodicidade em dia, conforme segue:

coloca em dia a periodicidade desta que é uma das mais conceituadas revistas da área de Letras e Lingüística no Brasil. Felizmente, sempre foi possivel contar com o apoio de colegas de diferentes instituiçôes para manter a qualidade de nossa revista. Esses colegas, além de enriquecerem a revista com sua participação, também muito auxiliam ao autorizarem a publicação de seus textos mesmo quando, por motivos alheios à vontade de todos, as ediçōes não são tão pontuais como gostaríamos. A todos o nosso muito obrigado.

$\mathrm{Na}$ Organon 43, sob a temática "Metáfora em perspectiva", é reiterado o papel da revista na divulgação de trabalhos de pesquisadores da UFRGS 
e de outras universidades brasileiras, mas o que mais nos chama a atenção no Editorial deste número é a discussão conceitual à qual se dedicam os editores, pois eles colocam em questão os modos de nomear a ciência linguística, as contradições que se evidenciam no contraponto entre o que é e o que não é fazer científico em termos de estudos da linguagem, chegando à conclusão de que:

Independentemente de ser a lingüística ciência ou năo, ou da pertinência da expressāo estudos da linguagem quando aplicada ao que era recoberto pelo termo lingüística, o que se vê é a mutação histórica na condição epistemológica desse saber. Essa mutação deverá ainda ser avaliada quanto aos seus aspectos de herança que advém do passado para que se possa, então, estabelecer as perspectivas do presente.

A Organon número 44/45 reafirma mais uma vez a importância da Revista para a área dos Estudos da Linguagem, conforme podemos observar no recorte que fizemos do seu Editorial:

É com imensa satisfaçăo que apresentamos este número duplo da Revista Organon, organizado pela professora Dra. Maria Cristina Martins, com o tema Os Estudos Históricos e Comparativistas na Atualidade. Os estudos ora reunidos, de pesquisadores e professores de diversas instituições, constituem uma mostra significativa dos estudos de língua realizados no campo diacrônico e comparativista.

A Organon número 46, sob a temática "Aquisição da linguagem: diferentes perspectivas", traz em seu Editorial, mais uma vez, a importância de manutenção da periodicidade em dia, bem como a importância da temática em destaque para a área de Letras; no entanto, o que nos chama especial atenção é de que, nesse momento, já não se trata mais de subáreas como os demais números, pois neste a Linguística aparece assim nomeada, enquanto os Estudos Literários passam a Estudos de Literatura, vejamos:

a revista Organon está mais viva do que nunca. Sua periodicidade está em dia e, 0 mais importante, seus colaboradores estão entre os mais destacados da Linguistica e dos Estudos de Literatura.

A Organon número 47, publicada em 2009, sob a temática "Políticas e práticas sociais de resistência", revela-se como diferencial em relação às demais edições, pois não se coloca nem como própria aos Estudos da Lin- 
guagem, nem como aos Estudos Literários, conforme podemos observar na Apresentação que fazem as organizadoras: "Assim, nossa contribuição, através deste número da Revista Organon, vem ao encontro de diferentes leituras sobre essas práticas e discursos de resistência, desenvolvidas por colegas das áreas da Literatura, da Lingüística e da História (ZANDWAIS; TUTIKIAN, 2009, p. 1).

Da mesma forma, observamos, no Editorial, que este número da Organon faz funcionar com mais força a nomeação da área que antes era "Estudos da Linguagem" e que passa a ser Linguística, não mais fazendo par com "Estudos Literários", mas com Letras, acenando para o quadro político-institucional das grandes áreas do $\mathrm{CNPq}$, reconhecidas atualmente como as que determinam as divisões internas e as distribuições de recursos financeiros. Eis o recorte:

\footnotetext{
A Organon - Revista do Instituto de Letras da Universidade Federal do Rio Grande do Sul - tem uma tradição de mais de $\mathbf{5 0}$ anos, circulando como periódico reconhecido e prestigiado no âmbito acadêmico brasileiro e fora dele. Sua política editorial abre espaço para divulgação dos trabalhos de pesquisadores e professores destacados nas áreas de Letras e Lingūistica, buscando abranger as diversas perspectivas teóricas que tratam dos temas atinentes ao campo.
}

Interessante também destacar como a pesquisa vai se firmando e se instituindo pelo dizer do Editorial, como veremos com o aparecimento da nomeação "campo" junto à área e, ao mesmo tempo, vem nos atualizar as demandas e as especificidades do dizer na cientificidade marcadamente do final dos anos 2000, quando o próprio CNPq introduz tal nomeação para diferenciarmos área, campo e linha de pesquisa. E é neste número que se anuncia que a revista passará por reformulações, passando também a ser digital para acompanhar os demais periódicos da instituição que integram o sistema Qualis da CAPES. Dois órgãos de financiamento (CAPES e CNPq) que dão autonomia aos periódicos, ao mesmo tempo, os controlam através de uma política de avaliação, de certificação e distribuição de recursos.

A Organon 48, sob a temática "A pesquisa em Análise do Discurso no PPG-Letras/UFRGS e sua expansão institucional”, traz à baila a palavra pesquisa já no tema e vai reforçar tal elemento no Editorial, conforme segue:

O presente número 48 da Revista Organon do Instituto de Letras da Universidade Federal do Rio Grande do Sul reveste-se de uma importância singular para todos aqueles que integram e acompanham as atividades de pesquisa desta Unidade de 
Ensino. Particularmente aos que se sentem concernidos pelas questões do discurso, de suas distintas materialidades e de seus múltiplos pontos de abordagem teórica e metodológica (FERREIRA, 2010).

A Organon número 50, sob a temática "TERMISUL 20 anos: Terminologia, Terminografia e Tradução", como o próprio tema sugere, é uma edição comemorativa ao projeto de pesquisa que estuda a terminologia no sul do Brasil, o qual teve apoio de órgãos de fomento no decorrer desses anos, pois as organizadoras destacam, na Apresentação, a importância dos recursos obtidos junto à FAPERGS e ao CNPq. É importante lembrar que tal tema e resultados de pesquisa já vinham sendo divulgados no número 26 (conforme já tratado anteriormente). Ainda em 2011, foi publicada a Organon número 51, sob a temática "Bilinguismo/aprendizagem da L2 e processos cognitivos", no qual o enfoque central foi dado à "abordagem multidisciplinar, mostrando a complexa rede que envolve a pesquisa sobre linguagem, abarcando áreas vizinhas como a Psicologia, a Educação e as Neurociências" (FERREIRA, 2011).

A Organon número 53, sob a temática "Autoria nas/entre linhas", marca mais uma vez as constantes relações das áreas do conhecimento, não dividindo mais um número da Revista para Linguística e outro para Literatura, como pode ser observado no Editorial: "o leitor deverá percorrer os intrincados caminhos da Análise do Discurso, da Linguística, da Literatura, das Artes e da Psicanálise para tentar (des)cobrir a autoria nas/ entre linhas" (FERREIRA, 2012). Tal número é o primeiro que passa a integrar a Plataforma de Periódicos Científicos SEER, movimentando, a partir de então, duas edições: a impressa e a eletrônica.

A Organon número 54, sob a temática "Fonologia: Variação e mudança", traz, em seu Editorial, elementos que revelam o momento de consolidação da revista, posto que nesse momento se tem "pesquisadores conhecidos por sua longa experiência no campo dos estudos fonológicos e que representam os diferentes grupos de pesquisa que atuam com prestígio no país" e "a presença de pesquisadores nacionais e estrangeiros, mostrando como o Brasil se situa na vanguarda da pesquisa que se faz nessa área da teoria e análise linguística"; e assim "o que muito favorece a consolidação do prestígio e tradição de nossa Revista Organon no campo das Letras no cenário nacional e internacional" (FERREIRA, 2013).

Por fim, o número 56, da Organon, destinado aos estudos que apresentam reflexões sobre o "Latim ontem e hoje", no qual não está posta a 
divisão entre Linguística e Literatura, pois, como escrevem os organizadores, na parte da Apresentação, "o presente volume é constituído por 17 artigos de autores filiados a diversas universidades brasileiras e estrangeiras, abordando a relação do latim com a linguística, com a literatura, com a filologia, com o ensino". Já no Editorial é explicitado o papel institucional da UFRGS na manutenção do ensino e da pesquisa em línguas clássicas conforme segue:

O Instituto de Letras da Universidade Federal do Rio Grande do Sul orgulha-se de preservar em seu currículo o ensino das línguas clássicas, quase uma exceção no quadro das Instituições Públicas Federais. Nesse sentido, a Organon, Revista do Instituto de Letras, sente-se realizada de poder contribuir com a discussão qualificada do tema, por meio do atual número, certamente um marco relevante para os estudos da área.

Portanto, podemos considerar a Organon como espaço de circulação do conhecimento sobre a linguagem que, aos poucos, vai se constituindo na sua ordem disciplinar tal como a concebemos hoje e segundo uma especificidade instada em determinada ordem discursiva que se ancora em um institucional já marcado historicamente. Sustentamos essa reflexão ao tomar a universidade como lugar de institucionalização e legitimação da pesquisa científica, pois a produção do conhecimento científico precisa legitimar-se institucionalmente para poder sustentar os laços entre produzir ciência e fazer circular tal produção (Lagazzi-Rodrigues, 2002). Se a pesquisa é, então, inerente ao papel da universidade, principalmente de uma universidade pública em seu tripé - ensino, pesquisa e extensão -, a divulgação e a circulação do conhecimento também fazem parte de suas atribuições, mas é impossível pensar sobre esses dois processos sem um institucional e sem referendo de uma agência de fomento. O que queremos mostrar é que o institucional, espaço de controle do que o pesquisador pode e não pode dizer, é também amparado, no seu controle, por políticas de financiamento e também de referenciação (Auroux, 2007) e certificação, pois sem o institucional e a certificação no científico-acadêmico, produzimos para quem?

Assim, as revistas científico-acadêmicas constituem-se como um dos instrumentos fundamentais para o político na divulgação e na circulação do conhecimento, pois delas depende toda uma ordem institucional do que pode e deve ser dito, do que pode e deve ser pesquisado institucio- 
nalmente. Nos apoiamos em Auroux (2007), quando ele afirma que as comunidades de conhecimento "sont normatives et foctionnent à l'aide de la reconnaissance par les pairs (éducation, comités, d’experts, jurys, etc.) et, conséquemment, par exclusion. Il n'y a pas de science sans extérieur. Les communautés ont une fonction sociale générale de validation et de légitimation"20 (p. 151).

Consideramos pertinente trazer à baila o que já levantávamos em 2008, no texto "Dos domínios e das Fronteiras: o lugar fora do lugar em outro e mesmo lugar" quando afirmávamos que "a produção do conhecimento não se dá em linha reta, de forma retilínea. Produzir ciência é produzir conhecimento em uma certa ordem, em uma certa época, em certas condições de produção [...] Produzir conhecimento é um trabalho permanente de demarcação de lugar, de lugares" (SCHERER, 2008, p. 133). Não queremos dizer com isso que, ao apresentarmos nossos recortes analíticos, neste estudo, temos o objetivo de demarcar lugares, mas cabe ressaltar que, de certa maneira, estamos trazendo à tona tanto os lugares já demarcados e estabilizados como aqueles que foram/são apagados e como estes produzem efeitos de sentido na história da própria revista.

\section{Pontos a reter}

"L'historien des idées linguistiques est au fond devant deux types de phénomènes: la permanence, ou au contraire les changements, plus au moins marquée, lémergence de théories et de concepts nouveaux"21 (Colombat; Fournier; Puech, 2010, p. 241).

A descrição e a interpretação propostas nesse estudo nos permitem produzir e fazer compreender a intriga que criamos nessa narrativa, a partir de dois movimentos de constituição da Organon que projetamos, ou

20 "Essas são normativas que funcionam com a ajuda do reconhecimento dos pares (educação, comitês, de especialistas, de júris, etc.) e, consequentemente, por exclusão. Não há ciência sem exterior. As comunidades tem uma função social geral de validação e de legitimação (2008, p. 129-130)" Tradução: Mariângela Pecciolli Gali Joanilho.

21 Tradução nossa: "O historiador das ideias está, no fundo, diante de dois tipos de fenômenos: a permanência ou, ao contrário, a mudança, mais ou menos marcada, emergência de teorias e de conceitos novos". 
seja, o primeiro, da institucionalização ao científico; e, o segundo, do científico ao disciplinar. Vejamos:

- Institucionalização: inicialmente não há determinação de área ou de quem pode publicar; o que se movimenta na direção de uma política editorial mais explícita e contundente.

- Formação de pesquisadores: objetivado, num primeiro movimento, por técnicas e métodos de pesquisa; e, num segundo movimento, pela consolidação da pesquisa, via titulação.

- Língua estrangeira: é dado como espaço cultural de interlocução, estabelecendo relações internacionais; depois, faz parte do sistema de avaliação e é obrigatória para a qualificação da revista.

- Cultura material: da era a da máquina de datilografia ao aparato tecnológico da cultura digital.

- Estabelecimento de fronteiras: a passagem do regional, incluindo sua abrangência aos países do Prata; passando a uma abrangência nacional e internacional, tal como as compreendemos hoje.

- Momento sócio-histórico: o atravessamento de um regime de exceção pelo silenciamento na produção e na publicação da revista por um período de quase duas décadas; e a refundação com a abertura política.

- Regularidades: vontade política de qualificação e de periodicidade que funcionam como fio condutor observável nos dois movimentos de constituição da revista.

- Financiamento: num primeiro movimento, ele não está explícito, o que vai acontecer no segundo movimento pelas políticas de avaliação e implementação de revistas acadêmico-científicas pela CAPES, levando a universidade a promover editais de financiamento.

\section{BIBLIOGRAFIA}

AUROUX, S. La question de l'origine des langues, suivi de L'historicité des sciences. Paris: PUF, 2007.

CHEVALIER, J.-C. La création des révues dans les années 1960. Matériaux pour l'histoire recente de la linguistique em France. In: CHEVALIER, J.-C; ENCREVÉ, P. Combats pour la linguistique, de Martinet à Kristeva. Lyon, FR: ENS Éditions, 2006. p. 309-360. COLOMBAT, B.; FOURNIER, J.-M.; PUECH, C. Histoire des idées sur le langage et les langues. Paris, FR: Klincksieck, 2010.

DASTON, L.; GALISON, P. Objectivité. Paris, FR: Les Presses du réel, 2012. 
FERREIRA, M. C. L. Editorial. Revista Organon. 2011, n. 50.

FERREIRA, M. C. L. Editorial. Revista Organon. 2012, n. 53.

FERREIRA, M. C. L. Editorial. Revista Organon. 2013, n. 54.

FERREIRA, A.C. A lingüistica entre os nomes da linguagem - uma reflexão na história das idéias lingüisticas. 2009. Tese (Doutorado em Doutorado em Lingüística) - Universidade Estadual de Campinas.

FLORES, V. N.; MELLO, A. M. L. de. Editorial. Revista Organon, 2005, n. $38 / 39$.

GUIMARÃES, A. M. M. Editorial. Revista Organon, 1989, n. 16, p. 8-9. GUIMARÃES, E. História da Semântica - Sujeito, Sentido e Gramática no Brasil. Campinas: Pontes, 2004.

GUIMARÃES, E. A língua portuguesa no Brasil. In: Ciência e Cultura, vol .57, n. ${ }^{\circ}$ 2, São Paulo abr./jun. 2005. Disponível em http://cienciaecultura. bvs.br/scielo.php?pid=S0009-67252005000200015\&script=sci_arttext, acesso em 01 de abril de 2013.

INDURSKY, F. Editorial. Revista Organon. 1997, n. 25.

INDURSKY, F. Editorial. Revista Organon. 2000, n. 28/29.

INDURSKY, F. Editorial. Revista Organon. 2002, n. 32/33.

INDURSKY, F. Editorial. Revista Organon. 2003, n. 35.

KRIEGER, M. G. Terminologia e integração: um projeto para o Mercosul (apresentação). Revista Organon, 1998, n. 26.

LAGAZZI-RODRIGUES S. O político na linguística: Processos de legitimação e institucionalização.In: ORLANDI, E. P. (org) Política linguística no Brasil. Campinas, SP: Pontes, 2007.

LAZZERI, C. La production des instituitions. Besançon, FR: Presses Universitaires Franc-Comptoise, 2002.

LATOUR, B. in DASTON, L.; GALISON, P. Objectivité. Paris, FR: Les Presses du réel, 2012.

MONARETO, V. Editorial. Revista Organon. 2004, n. 36.

PFEIFFER, C.C. Lingüística e institucionalização no espaço brasileiro. Texto apresentado no XXIII Encontro Nacional da ANPOLL, 2008. Disponível em: <http://www.anpoll.org.br/eventos/enanpoll2008>. Acesso em: 28.jul.2011.

SCHERER, A. E. Dos domínios e das fronteiras: o lugar fora do lugar em outro e mesmo lugar. In: SARGENTINI, V.; GREGOLIN, M. R. (orgs). Análise do discurso:heranças, métodos e objetos.São Carlos, SP: Claraluz, 2009.

A História e a memória na constituição do discurso da Linguística Aplicada no Brasil. In: Maria José Coracini; Ernesto Sergio Bertoldo. 
(Org.). O desejo da teoria e a contingência da prática: discurso sobre/na sala de aula. Campinas: Mercado de Letras, 2003, v., p. 061-084.

SCHERER, A. E.; PETRI, V. Os Homens que Compraram Madrugadas... Pereira Coruja e Walter Spalding na História do falar gaúcho. In: MASSMANN, Débora; CINTRA, Greciely. Linguagem e Historicidade. Campinas, SP: RG Editora, 2012. p. 59-76.

ZANDWAIS, A.; TUTIKIAN, J. . Apresentação. Revista Organon. 2009, n. 47. Recebido em: 10/07/2015. Aceito em: 10/08/2015. 